\title{
Behavior of powder particles on melt pool surfaces
}

\author{
Joerg Volpp ${ }^{1}$
}

Received: 23 July 2018 / Accepted: 26 December 2018 / Published online: 24 January 2019

(C) The Author(s) 2019

\begin{abstract}
Additive Manufacturing is in progress to change the production and manufacturing environments and possibilities; however, the complex processes taking place are not completely understood yet. A better understanding of the incorporation mechanism of the particles into the melt pool during blown powder processes could lead to methods to increase the powder and energy efficiency. Therefore, the incorporation mechanism was investigated in experiments and simulation. High-speed images made it possible to observe the behavior of single particles on the melt pool. A model based on the temperature-dependent surface tension/energy difference between the particle and the melt pool calculated the time until particle incorporation. It was shown that the surface tension characteristics during particle heating can even lift the particle from the melt pool. The calculated wetting behavior in combination with high kinetic energies should lead to an immediate immersion of the particle into the melt pool. Since observations do not show this behavior, it is concluded that the surface tension plays a role in the incorporation mechanism, but other effects like the occurrence of oxide layers or additional particle heating by the laser beam seem to lead to different mechanisms and heat conductions to support an earlier incorporation.
\end{abstract}

Keywords Laser additive manufacturing $\cdot$ Powder particle $\cdot$ Surface tension $\cdot$ Direct metal deposition

\section{Introduction}

Building structures from wire or powder material for creating [1] or repairing [2] industrial parts are the main driving forces and applications of Additive Manufacturing in production. The use of wire or powder material makes it possible to create the desired geometries without wasting much material compared to subtractive machining. Thereby, the production of parts from expensive base materials or bigger structures becomes more attractive. In addition, complex geometries can be realized [3], like overhangs to build, e.g., light-weight designs [4].

Additive Manufacturing processes are based on the accumulation of applied material and usually melting to form the desired geometry of a new part. The additional material is usually applied as wire or powder.

Powder application is realized either by pre-placing the powder in a powder bed (SLM, Selective Laser Melting; LMD, Laser Metal Fusion; Powder Bed Fusion) or by

Joerg Volpp

Jorg.volpp@ltu.se

1 Department of Engineering Sciences and Mathematics, Luleå University of Technology, 97187 Luleå, Sweden depositing blown powder to the processing zone (DMD, Direct Metal Deposition; DLD, Direct Laser Deposition; LMD, Laser Metal Deposition) to build tracks and layers to form a structure.

Direct Metal Deposition (DMD) of powder material utilizes a heat source, e.g., a laser beam, to heat the base material and mainly melt the deposited material. Powder particles can be applied by a powder nozzle directed in leading or trailing position [5], while modern powder nozzles use coaxial designs (e.g., [3]). Coaxial nozzles enable a direction independent and highly focused powder application into the processing zone. The laser beam can be either positioned in the center, while the powder is applied around the laser beam or by leading the powder through a central nozzle, while the laser beam is lead around (e.g., [6]). Depending on the application direction of the powder particles, their heating conditions can vary, since they spend different times inside the laser beam, e.g., Han et al. [7] found that the shadow of the particle cloud significantly influences the melt pool shape. Therefore, the incorporation mechanism is important to understand to make the process more efficient in order not to waste powder material.

Different observations were made about the condition of the applied powder. Peyre et al. [8] calculated in their analytical model that no particle melting should take place, while Pinkerton et al. [9] found that powder particles can be heated 
to reach almost melting temperature when applied through a coaxial nozzle. The model from Qi \& Mazumder [10] showed that the particles heat up to melting temperature within $10^{-4} \mathrm{~s}$ after arriving on the melt pool. Partes [11] could show that melting of the particle surface is possible when they show low melting temperature, low heat conduction, and a good laser beam absorption.

In addition, Jouvard et al. [12] calculated the heating of the powder particles and concluded that the cladding processes need a molten pool to be able to work. This effect was recently confirmed, since the interaction time between liquid particles and the solid substrate in regularly used setups would be too short to ensure the heat transfer from the particle to the substrate for solidification [13].

Depending on the condition of the powder particles when arriving on the melt pool surface, different aspects can define their incorporation:

- Heating of the particles can take place when irradiated by the laser beam and by thermal radiation from the processing zone, which should support the incorporation.

- Particle sizes define the kinetic energy and the energy needed for complete melting [14].

- The kinetic energy of the particle can influence the incorporation [14].

- Surface-tension-driven wetting mechanisms can occur [14].

It was shown in [15] that the particle kinetic energy seems to have a minor impact on the powder particle incorporation. All observed particles that arrived on the melt pool remained part of the track, independently from their speed; however, the particle behavior concerning incorporation duration varied depending on their landing zone.

The different observations about the particle temperatures in literature seem to be reasonable since the particles can take different paths to the processing zone experiencing different heating cycles. When using coaxial nozzles, the particles are not supposed to pass through the high intense areas of the laser beam before arriving on the melt pool. Therefore, it can be assumed that mainly non-melted powder particles arrive on the melt pool surface.

Then, wetting mechanisms of the melt and the particles can occur. The main role during the wetting process plays the surface tension (liquid part) and surface energy (solid part) of the components. Wetting is a mechanism that involves the liquid (l), solid (s), and the surrounding gaseous (g) component. The wetting angle can be described considering the related surface energy $\sigma_{s g}$, surface tension $\sigma_{l g}$, and interfacial energy $\sigma_{l s}$ (Young-equation)

$\cos (\theta)=\frac{\sigma_{s g}-\sigma_{l s}}{\sigma_{l g}}$
The surface tension between a solid or a liquid material is given in comparison to the surrounding gas. It is well-known that the surface tension is temperature $(T)$ dependent, e.g., Keene [16] summarized the surface tension $\sigma$ values and thermal dependencies

$\sigma(T)=\sigma_{m e l t}-\frac{d \sigma}{d T} \cdot\left(T-T_{m}\right)$

with the melting temperature $T_{m}$, the material-dependent surface tension at melting temperature $\sigma_{\text {melt }}$, and the surface tension gradient $\frac{d \sigma}{d T}$.

The equivalent value for solid materials is usually named surface energy and is also temperature-dependent [17]. The surface tension between a solid and a liquid is called interfacial energy, which can be derived from Eq. 1, when the wetting angle was measured in experiments (e.g., [16]).

The extent, to which the final state of spreading can be reached depends also on the viscosity of the liquid and the time until solidification [18]. In powder application processes, the energy transfer direction is from the melt pool to the particle. Therefore, the particle heating will increase its temperature and depending on the thermal conditions even melt the particle.

Due to the high temperatures in the processing zone and the fast process effects, the possibilities of observations of the particle incorporation are difficult. High-speed imaging was used to observe characteristics of the particle interaction with the melt pool (e.g., [15]). These observations showed that all particles arriving on the melt pool are either incorporated when landing in the hot areas around the laser beam or remain on the track after solidification. Immediate incorporation was detected when powder particles land in the vicinity of the laser irradiation and was measured to $0.05 \mathrm{~ms}$. In the surrounding melt pool zone, the particles float in average $0.125 \mathrm{~ms}$ until they incorporate.

The powder incorporation is the main mechanism that defines the powder particle usage efficiency and thereby the cost and environmental impact when building an additive part. In addition, the track geometry depends on the powder particle input. A better understanding of the powder particle behavior can lead to more efficient ways and possibilities to control the blown powder processes. In this paper, the incorporation process is further evaluated to identify the main driving forces that define the incorporation of powder particles into the melt pool. It is suggested that the incorporation is based on the wetting mechanism resulting from the difference of surface tensions due to temperature differences. 


\section{Methodology}

\subsection{Setup and materials}

For the experiments, the setup visualized in Fig. 1 was used.

A continuous wave laser illumination (IPG Photonics, wavelength $1070 \mathrm{~nm}$ ) of $1.5-\mathrm{kW}$ output power and $3-\mathrm{m} / \mathrm{min}$ processing speed was used. Powder particles were applied using a coaxial nozzle (COAX14, Fraunhofer IWS) at a transport gas flow rate of $5 \mathrm{l} / \mathrm{min}$ and a powder feed rate of $8 \mathrm{~g} / \mathrm{min}$. Argon was used as transport and shielding gas. The powder focus was positioned on the material surface, while the laser beam was defocused $20 \mathrm{~mm}$ below the surface resulting in a spot diameter of $2.8 \mathrm{~mm}$ on the material surface. Powder and base material were $316 \mathrm{~L}$ stainless steel. Powder size distribution of the chosen powder was from 50 to $100 \mu \mathrm{m}$. A highspeed camera (Photron Fastcam mini UX 100) and an illumination laser (Cavitar cw diode laser) were positioned to observe the particle interaction with the melt pool.

\subsection{High-speed imaging}

High-speed imaging was done at a recording frequency of 12.500 Hz. Video sequences were evaluated to derive the powder particle behavior when interacting with the melt pool surface (Fig. 2).

The outline of the melt pool was identified in the highspeed videos by determining the moving surface transition to the solid material. Landing zones were defined depending on the observation of the typical behavior of the powder particles. Therefore, the time of particles floating on the melt pool was measured depending on their landing zone (Zones 1 to 4 in Fig. 2). Figure 3 shows the tracking of single particles and their movements on the melt pool.

Only particles that incorporated into the melt pool were considered. In addition, the average particle speeds of the

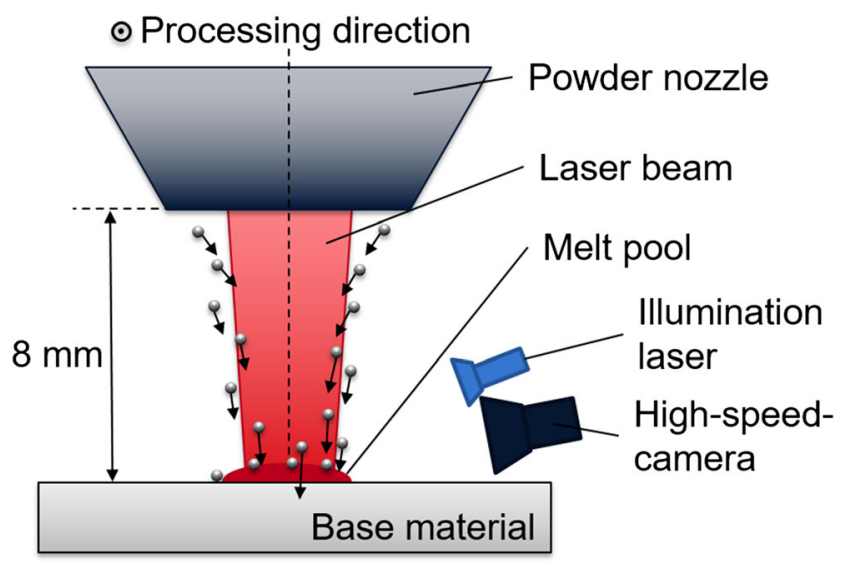

Fig. 1 Principle sketch of the experimental setup observed particles were measured by considering the distance of its movement from one frame to the following in combination with the recording frequency until incorporation.

\subsection{Incorporation modeling}

The aim of the modeling was the derivation of the particle floating duration until reaching the melt pool temperature. This condition was used as the indicator for incorporation, since the surface tension difference is still present.

Since two components (particle and melt pool) with different surface tension/energy due to their different temperatures interact, it can be assumed that wetting occurs according to Eq. 1. Figure 4 illustrates the possible behaviors of a particle when interacting with the melt pool. Depending on the material temperatures, different wetting angles can be expected leading to different heights $h$ of the particle inside the melt pool.

The developed model calculated the wetting angle according to Eq. 1 depending on the actual surface tension values at different temperatures of the particle and the melt pool. Table 1 lists the used values of the surface tension components for modeling. Since the thermal surface tension coefficient is negative, the surface tension decreases with increasing temperature.

Three modeling methods were used: static and temporal with and without particle movement.

The assumed particle diameter $d_{\text {part }}$ was chosen to $75 \mu \mathrm{m}$ as the average of the used powder spectrum. Assuming spherical particles with the density $\rho$, the mass of a particle is

$m=\rho \cdot \frac{4}{3} \cdot \pi \cdot\left(\frac{d_{\text {part }}}{2}\right)^{3}$

\subsubsection{Static model}

For the static model, it is assumed that the particles rest on the melt pool where they landed. Due to the large size of the melt pool compared to the size of the particle, the melt pool temperature was assumed to remain constant for the calculation. The wetting angle and the particle height in the melt pool were calculated from the initial surface tension/energy values according to Eq. 1. The heat $E$ that needs to be transferred from the melt pool to the particle for reaching melt pool temperature was then calculated at the assumed constant height of the particle in the melt pool following

$E=c_{p} \cdot m \cdot\left(T_{\text {base }}-T_{\text {part }}\right)+m \cdot L_{m}$

including the base metal melt pool temperature $T_{\text {base }}$, the particle temperature $T_{\text {part }}$, the heat capacity $c_{p}$, the mass $m$, and the energy need for melting using the latent heat of melting $L_{m}$. 
Fig. 2 High-speed imaging frame showing floating powder particles on the melt pool surface and the defined landing zones

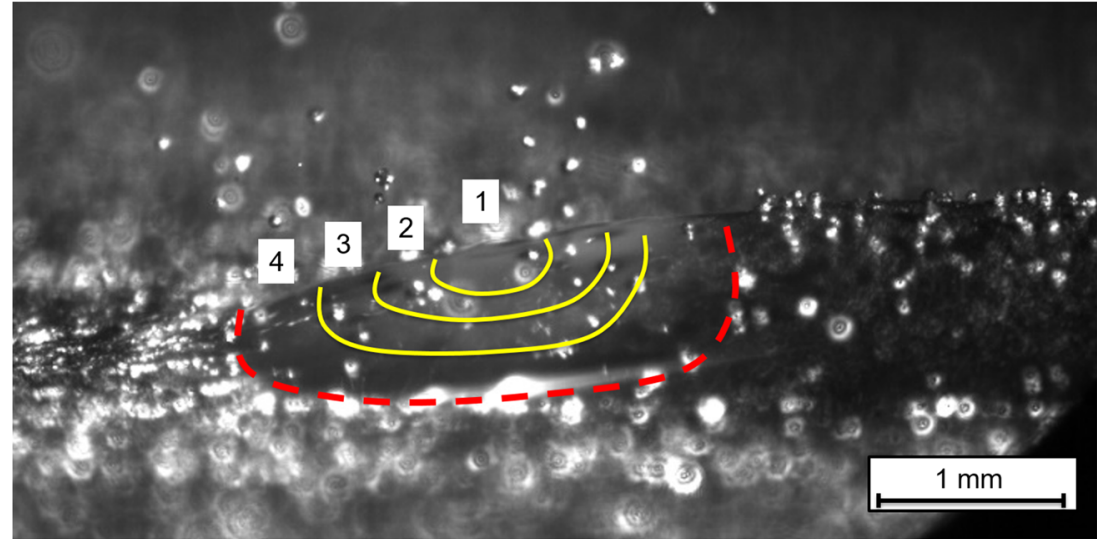

I Melt pool outline

\section{Zone border markings}

The time until the powder particle reaches the melt pool temperature was calculated. Reaching this stage, the surface tension values are the same for the particle and the melt pool, and the particle is assumed to incorporate. The contact angle $\alpha$ was derived using Eq. 1. The height $h$ of the particle inside the melt pool (Fig. 4) is

$h=d_{\text {part }}\left(1-\frac{\alpha}{180^{\circ}}\right)$.

The particle surface area $A$ that is in contact with the melt pool is then

$A=\pi \cdot d_{\text {part }} \cdot h$.

The time until the particle is completely molten is

$t_{\text {melt }}=\frac{E}{A \cdot\left(T_{\text {base }}-T_{\text {part }}\right) \cdot Q}$ with the heat flow

$Q=c_{p} \cdot m \cdot\left(T_{\text {base }}-T_{\text {part }}\right)+m \cdot L_{m}$

with the specific heat capacity $c_{p}$.

\subsubsection{Temporal model (no particle movement)}

In addition to the static modeling, the temporal model considers the change of the surface tension of the particle during its temperature increase due to its heating by the melt pool. The melt pool temperature is still considered constant during the calculation. Depending on the actual particle temperature, the surface tension value was recalculated in every time step and the new height in the melt pool was defined after each time step. For the modeling, the time until incorporation was defined as the time that it takes for transferring enough energy
Fig. 3 Sequence of high-speed images for tracking single particles

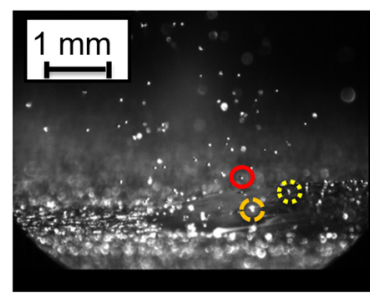

$0 \mu \mathrm{s}$

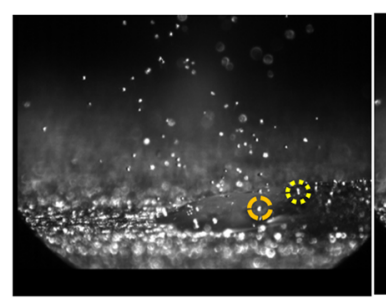

$240 \mu s$

O Immediate incorporation

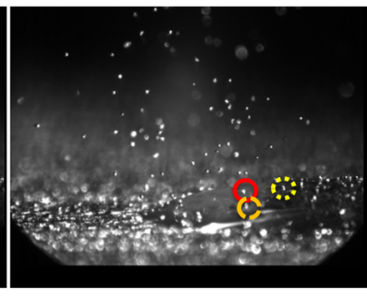

$80 \mu \mathrm{s}$

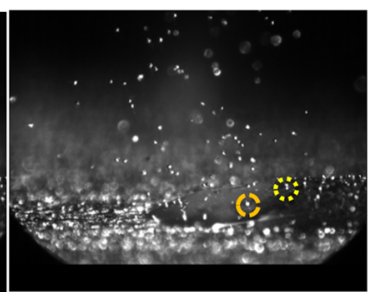

$320 \mu \mathrm{s}$

c) Floating and incorporation

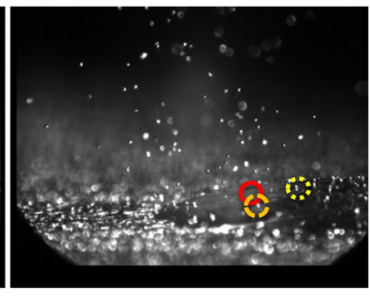

$160 \mu \mathrm{s}$

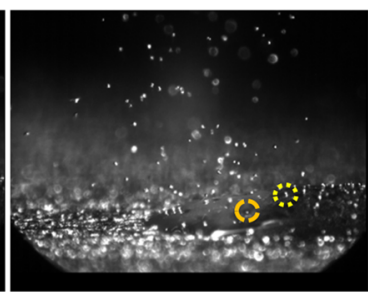

$400 \mu \mathrm{s}$

Resting particle 


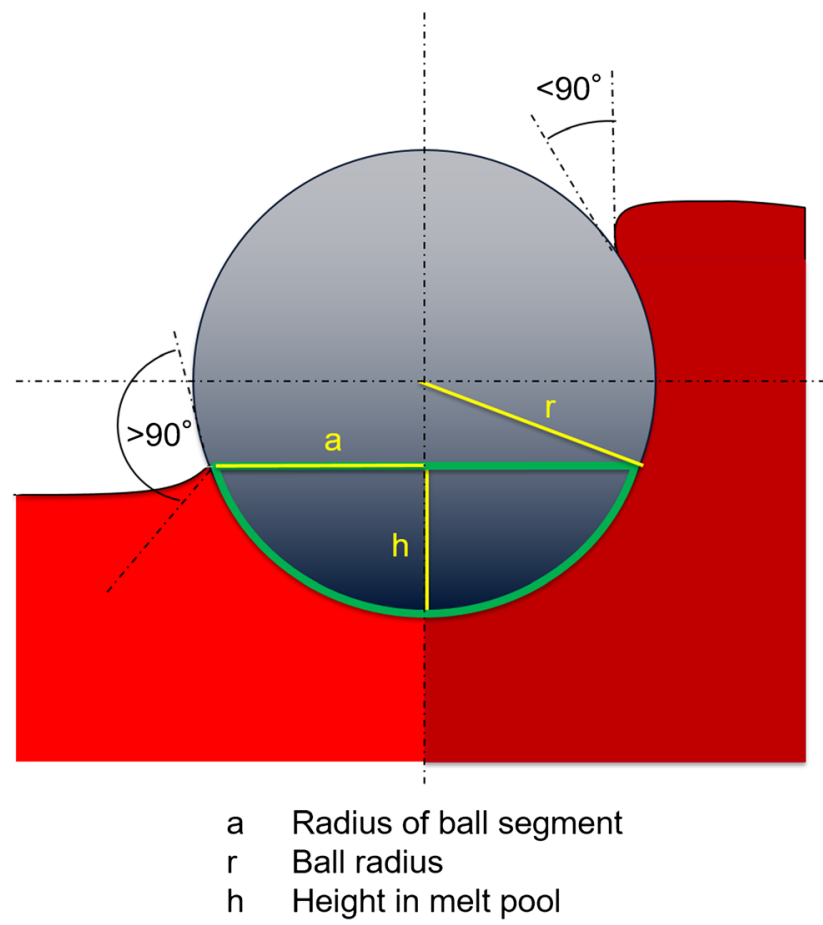

Fig. 4 Possible wetting situations (left: $>90^{\circ}$, right: $<90^{\circ}$ wetting angle) of a powder particle on a melt pool and geometrical measures (evaluated for the case $>90^{\circ}$ )

from the melt pool to the powder particle that the particle is molten (Eq. 4).

\subsubsection{Temporal model (including particle movement)}

This temporal model expands the previous temporal model considering the observed particle movement on the melt pool before incorporation. The experimentally measured particle speeds were taken to estimate the relative temperature increase of the melt pool that the particle experiences during its movement towards the laser beam. In the center of the melt pool, boiling temperature $T_{b}$ was assumed, which is in agreement with literature that identified keyhole occurrence during DMD processes (e.g., [20]).

In the model, the particle movement is considered by increasing the melt pool temperature. The temperature of the assumed round melt pool (radius $r$ ) at its edge is assumed to be melting temperature $T_{m}$ (Fig. 5).

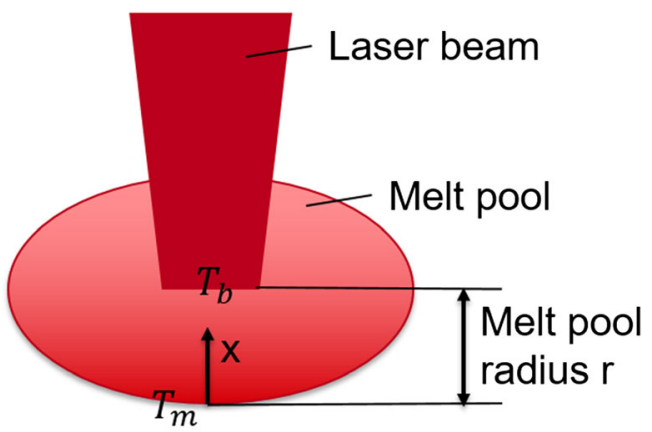

\section{Boiling temperature $T_{b}$ Melting temperature $T_{m}$}

Fig. 5 Melt pool assumptions for temperature calculation

The local temperature $T_{\text {melt }}$ pool at a certain radius $x$ starting at the edge of the melt pool was assumed to be linearly increasing from the melt pool edge to the melt pool center to describe the influence of a changing temperature of the melt pool on the particle heating and is calculated to

$T_{\text {melt pool }}=\frac{\left(T_{b}-T_{m}\right)}{r} \cdot x+T_{m}$

including the melting $T_{m}$ and boiling $T_{b}$ temperature of the material. The temperature increase along the $x$-axis (Fig. 5) is therefore

$T_{\text {grad }}=\frac{\left(T_{b}-T_{m}\right)}{r}$.

Considering the speed of the particle $v$ derived from the high-speed imaging evaluation, the melt pool temperature that the particle experiences $T_{i n c r}$ is

$T_{\text {incr }}=T_{\text {grad }} \cdot v$.

When the particle moves on the melt pool towards the melt pool center, the melt pool temperature that the particle experiences changes based on the temperature gradient.

The duration until incorporation is defined as before. The values that were used for modeling are summarized in Table 2 .

MatLab (R2017a) was used to implement the equations and conduct the simulation. The height in the melt pool and
Table 1 Surface tension/energy values

\begin{tabular}{llll}
\hline Material & $\begin{array}{l}\text { Surface tension/ } \\
\text { energy in } \mathrm{mN} / \mathrm{m}\end{array}$ & $\begin{array}{l}\text { Thermal surface tension } \\
\text { coefficient in } \mathrm{mN} /(\mathrm{m} * \mathrm{~K})\end{array}$ & Reference \\
\hline $\mathrm{Fe}$ (liquid) & 1909 & -0.52 & {$[16]$} \\
$\mathrm{Fe}$ (solid) & 2500 & -0.455 & {$[17]$} \\
Interfacial & 200 & - & {$[19]$} \\
\hline
\end{tabular}


Table 2 Modeling parameters

\begin{tabular}{lll}
\hline Parameter & Symbol & Value \\
\hline Time step size & & $10 \mathrm{e}^{-5} \mathrm{~s}$ \\
Particle diameter & $d_{\text {part }}$ & $75 \mu \mathrm{m}$ \\
Material density & $\rho$ & $7874 \mathrm{~kg} / \mathrm{m}^{3}$ \\
Latent heat of melting & $L_{m}$ & $0.268 \mathrm{~J} / \mathrm{kg}$ \\
Heat capacity [21] & $c_{p}$ & $444 \mathrm{~J} /(\mathrm{kg} \times \mathrm{K})$ \\
Melting temperature [21] & $T_{m}$ & $1538^{\circ} \mathrm{C}$ \\
Boiling temperature [21-Bra92] & $T_{b}$ & $2861{ }^{\circ} \mathrm{C}$ \\
Heat flow [22] & $Q$ & $25,000 \mathrm{~W} /\left(\mathrm{m}^{2} \times \mathrm{K}\right)$ \\
\hline
\end{tabular}

the duration until incorporation were evaluated at different initial particle and melt pool temperature combinations.

\section{Results}

\subsection{Particle observation}

The high-speed-imaging observation showed that the particles that land on the melt pool are made part of the track. Different landing zones as described in [15] were also observed in this work. Particles that land close enough to the laser beam can incorporate, while particles further away can remain on the surface of the track. It was observed that the particles that incorporate later, mainly move towards the laser beam before incorporation (e.g., [15]).

The duration until incorporation of the particles and the related particle speeds were measured depending on their landing zone (Fig. 6). The particle speeds and incorporation durations are the lowest in the central zone (zone 1). The incorporation time increases the further away the particle lands on the melt pool.

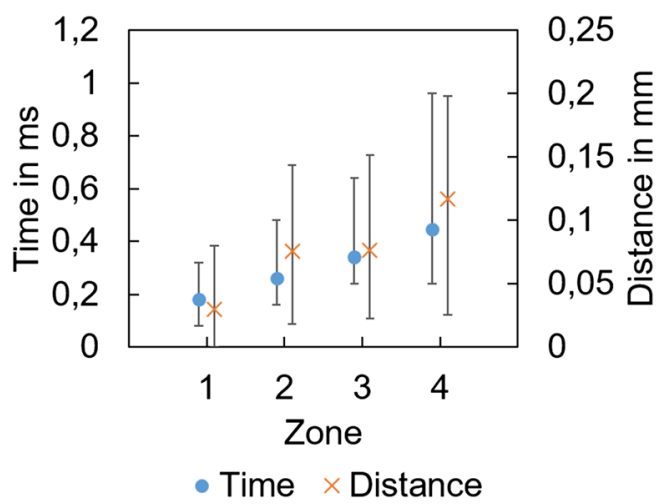

Fig. 6 Time duration from particle landing on the melt pool until its incorporation and average particle speed depending on the landing zone
Table 3 Temperature increase depending on the landing zone of the particle

\begin{tabular}{lcccc}
\hline In K/ms & Zone 1 & Zone 2 & Zone 3 & Zone 4 \\
\hline$T_{\text {incr }}$ & 49 & 120 & 102 & 106 \\
\hline
\end{tabular}

The measured average temperature increase per time due to the particle movement on the melt pool depending on the landing zone is summarized in Table 3.

\subsection{Static particle interaction calculation}

The calculation of the static model revealed the time from particle landing on the melt pool until incorporation at assumed no particle movement on the melt pool and no height change during heating by the melt pool (Fig. 7).

The initial wetting angles and derived heights of the particle inside the melt pool are shown in Fig. 8.

The calculation considers the latent heat of melting. Therefore, there is a slight non-linearity at particle temperatures around the melting temperature of $1500{ }^{\circ} \mathrm{C}$.

\subsection{Temporal particle interaction calculation}

The particle heating duration was calculated until the particle reaches the melt pool temperature at different initial particle temperatures and melt pool temperatures (Appendix, Fig. 13).

The temporal model without particle movement calculated the height change of the particle in the melt pool as visualized in Fig. 9.

The simulation shows that initially, a complete immersion of the particle is calculated for most calculated cases at high melt pool temperatures, while during the heating of the

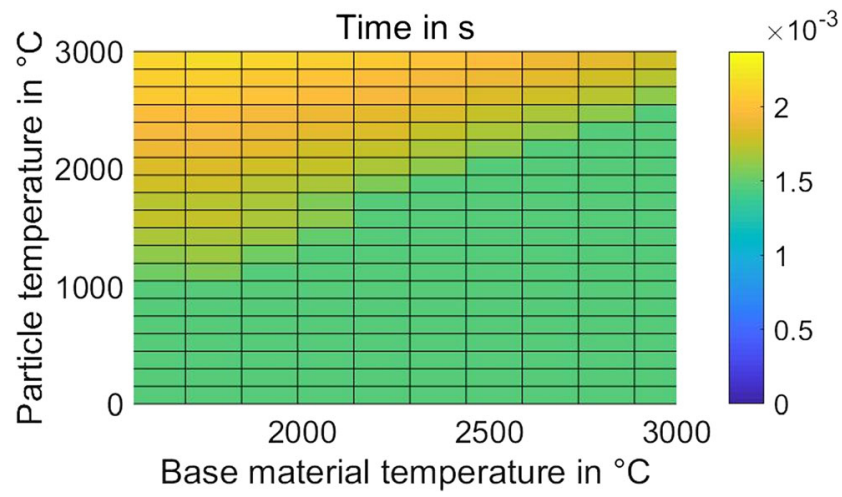

Fig. 7 Static calculation of the time duration from particle landing on the melt pool surface until incorporation at different particle and melt pool temperatures 


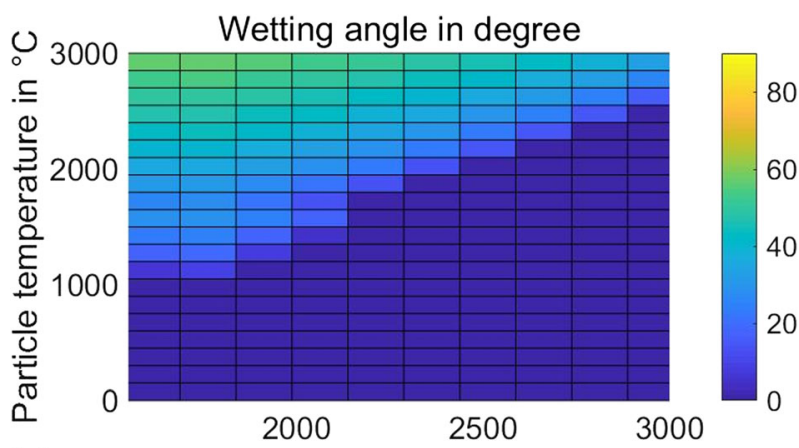

(a) Base material temperature in ${ }^{\circ} \mathrm{C}$

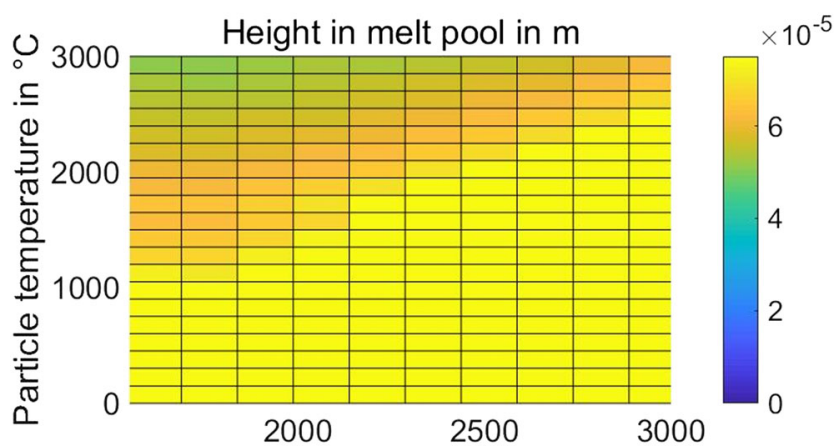

(b) Base material temperature in ${ }^{\circ} \mathrm{C}$

Fig. 8 Static calculation of $\mathbf{a}$ the wetting angle and $\mathbf{b}$ the height of the particle in the melt pool at different particle and melt pool temperatures

particle, the particle lifts out of the melt pool again until reaching the melt pool temperature.
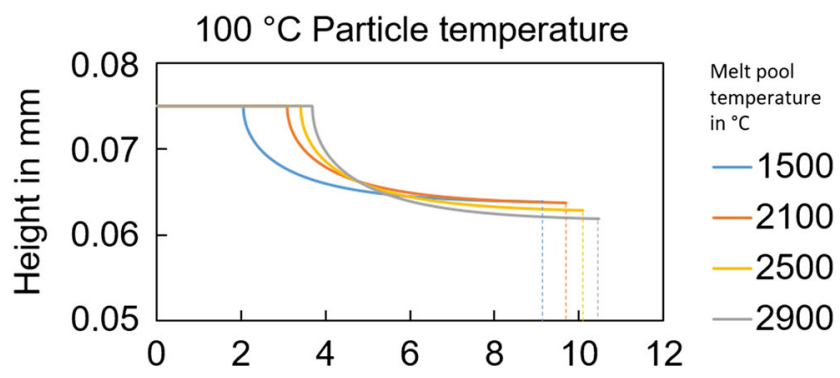

(a)

Time in ms

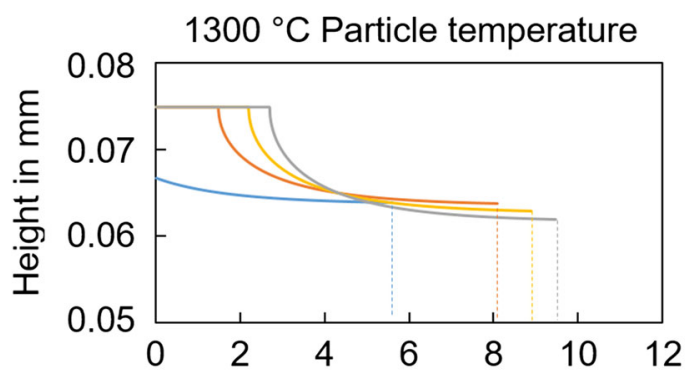

$\begin{aligned} & \text { Melt pool } \\ & \text { temperature } \\ & \text { in }{ }^{\circ} \mathrm{C}\end{aligned}$
-1500
-2100
-2500
-2900

(b)

Time in ms

Fig. 9 Temporal development of the particle height inside the melt pool of a particle arriving with $\mathbf{a} 100{ }^{\circ} \mathrm{C}$ and $\mathbf{b} 1300{ }^{\circ} \mathrm{C}$ initial temperature at different melt pool temperatures
When considering the particle movement on the melt pool and the related relative melt pool temperature increase, the incorporation durations become slightly longer (Appendix, Fig. 14), while the particle height inside the melt pool is lower at the end of the calculation at incorporation, which means that the particles stick out of the melt pool even more (Fig. 10).

The edges in the curves occur due to the different temperature increases of particle and melt pool when the particle melts.

The calculated incorporation durations derived from the temporal models are visualized in Fig. 11.

\section{Discussion}

The complex mechanism of the incorporation of powder particles into the melt pool was investigated. Due to the observed nature of the effect, it is suggested that the surface tensiondriven wetting mechanism can be an influencing factor on the incorporation mechanism.

When comparing the theoretically determined and experimentally measured particle floating duration on the melt pool until incorporation, it can be seen that the time in the calculation is slightly overestimated by the temporal model. Reasons might be the additional heating of the particles by the laser beam in the experiments, which was not considered in the model or the chosen stop condition, which defines the incorporation time. Perhaps the
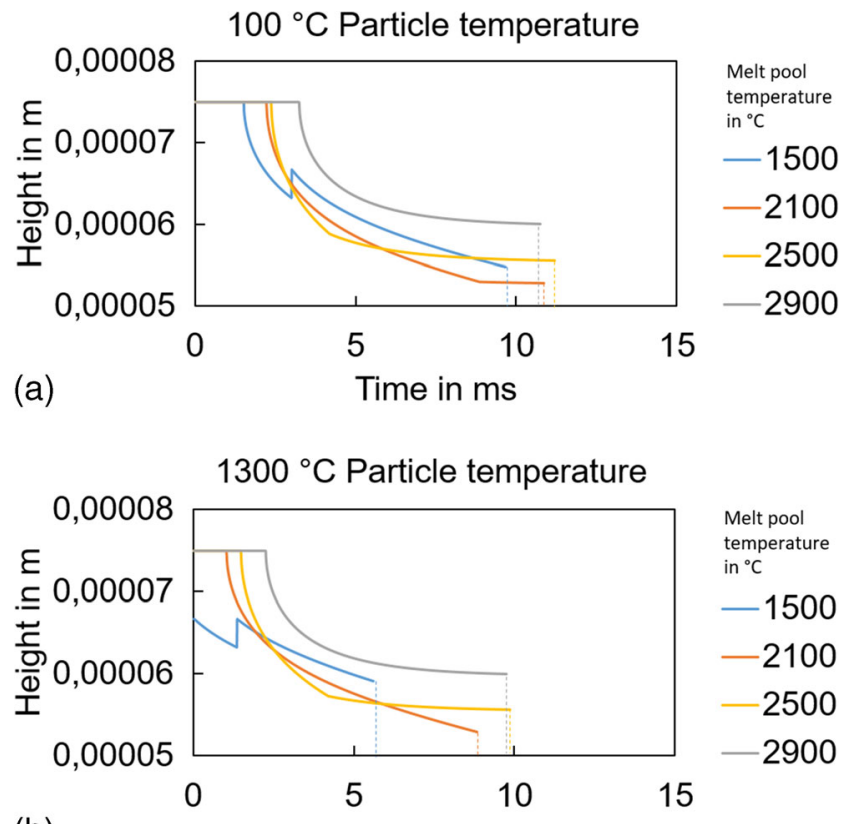

(b)

Time in $\mathrm{ms}$

Fig. 10 Temporal development of the particle height inside the melt pool of a particle arriving with $\mathbf{a} 100{ }^{\circ} \mathrm{C}$ and $\mathbf{b} 1300{ }^{\circ} \mathrm{C}$ initial temperature at different melt pool temperatures 


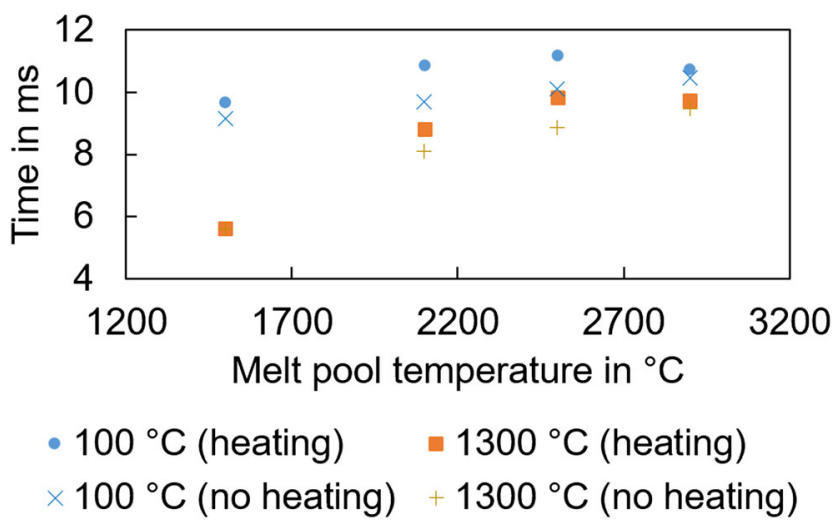

Fig. 11 Time until reaching melt pool temperature of particles with different initial temperatures calculated without and with considering melt pool temperature increase due to particle movement on the melt pool

incorporation can take place at temperatures that are even lower than the melt pool temperature as assumed for the modeling. It could be that the particle incorporates earlier than assumed in the calculation, when both components are liquid; however, the measured incorporation times are similar to the ones presented, e.g., by Qi \& Mazumder [10], who calculated the incorporation time to $10^{-4} \mathrm{~s}$ (100 $\mu \mathrm{m}$ steel particle).
The time until incorporation is mainly defined by the heating time until melting of the particle. Although the temperatures of the particles can significantly vary, the dimension of the incorporation times is similar (Fig. 11). Although the melt pool temperature increases during the particle movement, the incorporation duration can be even longer since the particles were calculated to be lifted from the melt pool, which results in a smaller contact area and a reduced energy transfer. The lifting was calculated to be more pronounced when the melt pool temperature increases due to the longer time until the particle reaches melt pool temperature and the surface tension decrease of the melt pool due to its temperature increase.

In the observed process, an untypical scenario of wetting occurs compared to other processes. Usually, a liquid drop wets on the surface (e.g., [18]), e.g., for surface tension measurement in, e.g., the Sessile drop method [23] or during brazing. During the DMD process, a solid particle is wetted by a liquid melt pool, while the wetting angle and the resulting height inside the melt pool can be calculated. The temperature-dependent surface tension values define the wetting characteristics.

The model calculated that in most conditions, perfect wetting should initially happen, which means that the particle should immerse completely and then be lifted from the melt
Fig. 12 Particle behavior at different temperatures of the particle and melt pool

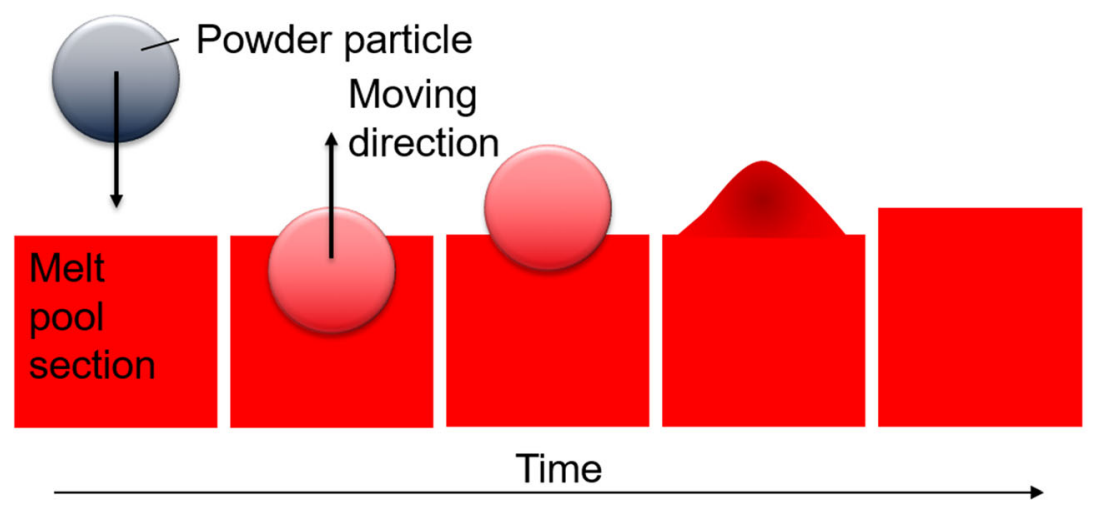

(a) Particle (slighlty below $\mathrm{T}_{\mathrm{m}}$ ) on melt pool (at $\mathrm{T}_{\mathrm{m}}$ )
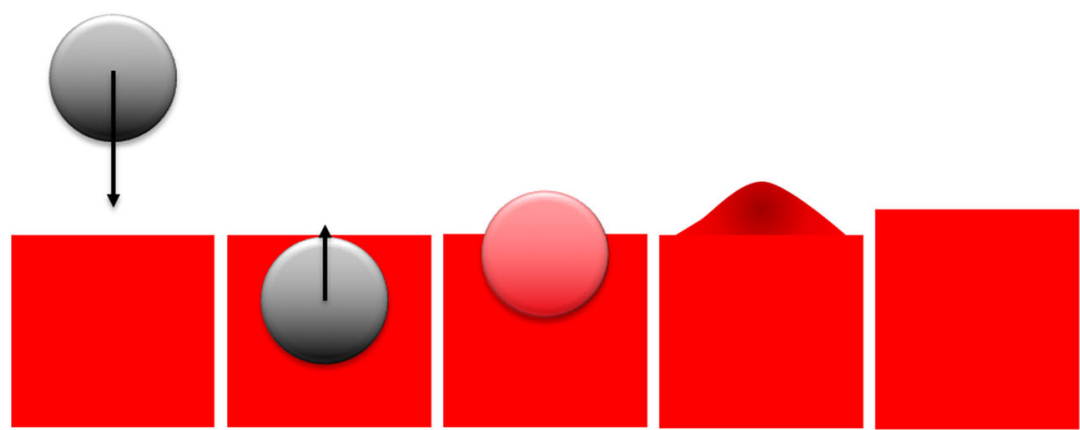

Time

(b) Big temperature difference between particle and melt pool 
pool during its heating (Fig. 12). This complete immersion of the particles was not observed in the experiments. It can be assumed that an additional mechanism takes place that keeps the particles floating on the melt pool. In addition, the kinetic energy could support the particle immersion due to the additional resulting force and the closing of the melt pool above it. It could be that a film, e.g., from an oxide layer on the surface could provide the immersion.

Since the particle floats on the melt pool and does not immerse completely as calculated, the effective area used for heat transfer should be even smaller than calculated in most observed cases in this work. Therefore, the incorporation time should be even longer. Since this was not observed in the experiments, it can be assumed that the earlier mentioned effect of an incorporation before reaching the melt pool temperature is most likely.

The observations and calculations show similar tendencies and dimensions. Therefore, the surface tension difference of the melt pool and the particle can be one of the reasons for the observed floating of the particles on the melt pool before incorporation; however, there must be other effects occurring that prevent the particle to incorporate immediately after landing as calculated by the presented surface tension-based model.

\section{Conclusions}

The comparison of calculated and experimentally measured time durations of particles from melt pool landing until incorporation reveals similar dimensions of the values. It can be assumed that the surface tension effect is one of the driving forces for the floating effect of the particle on the liquid melt pool.

The incorporation of a particle is faster at small differences of the temperatures of the particle and the melt pool and when the particle temperature is above the melt pool temperature.

However, the immersion of the particle into the melt pool is overestimated by the surface tension-based model compared to the experimental observations. Therefore, it is assumed that other effects like the impact of the oxide layer and additional particle heating by the laser beam prevent the particle from incorporation but lead to faster heating and melting.

It was shown that the surface tension-driven wetting mechanism can lead to a lifting of the particle from the melt pool due to temperature differences.

Funding information The authors acknowledge subcontracting from Fraunhofer ISW Dresden, Germany in the Agent3D project funded by the Bundeministerium fuer Bildung und Forschung (BMBF), Germany and the funding by VINNOVA - Sweden's innovation agency (project ÖVERLAG, no 2017-03240).

\section{Appendix}
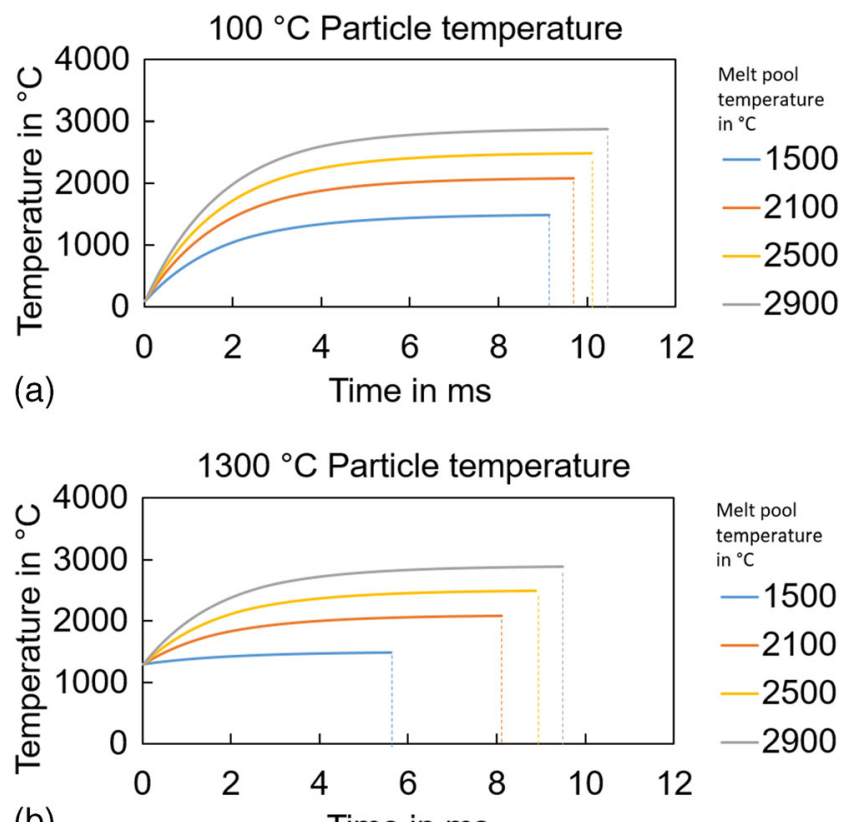

(b)

Time in $\mathrm{ms}$

Fig. 13 Calculation of the temporal development of the particle temperature inside the melt pool neglecting the particle movement on the melt pool of a particle arriving with a $100{ }^{\circ} \mathrm{C}$ and $\mathbf{b} 1300{ }^{\circ} \mathrm{C}$ initial temperature at different melt pool temperatures
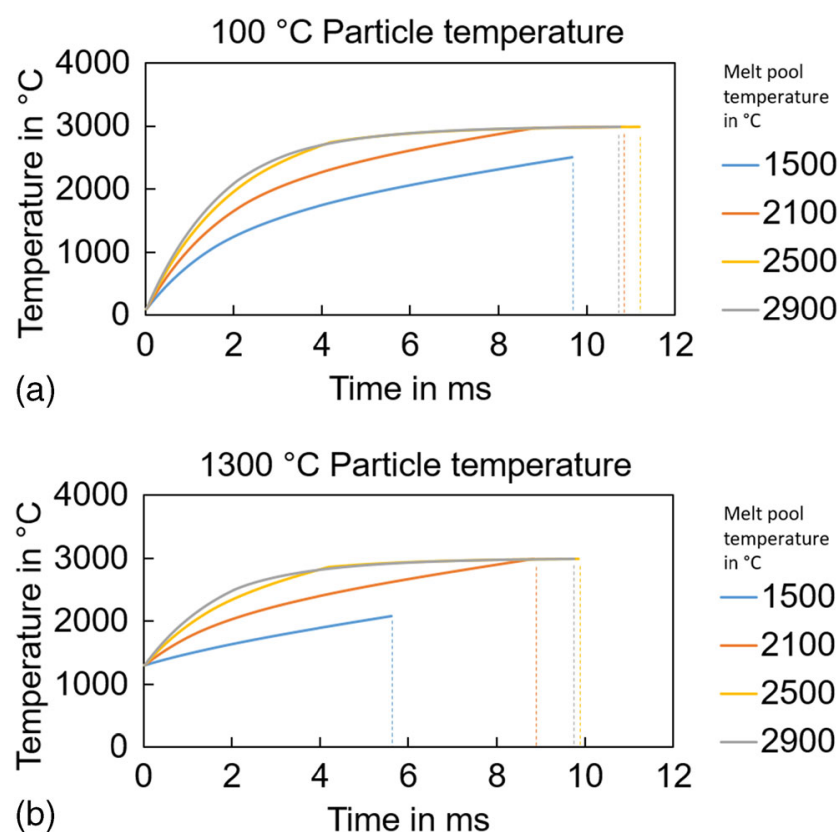

Fig. 14 Temporal development of the particle temperature inside the melt pool including the particle movement on the melt pool of a particle arriving with a $100{ }^{\circ} \mathrm{C}$ and $\mathbf{b} 1300{ }^{\circ} \mathrm{C}$ initial temperature at different melt pool temperatures 
Open Access This article is distributed under the terms of the Creative Commons Attribution 4.0 International License (http:// creativecommons.org/licenses/by/4.0/), which permits unrestricted use, distribution, and reproduction in any medium, provided you give appropriate credit to the original author(s) and the source, provide a link to the Creative Commons license, and indicate if changes were made.

Publisher's note Springer Nature remains neutral with regard to jurisdictional claims in published maps and institutional affiliations.

\section{References}

1. MacIntyre RM (1983) Laser hard surfacing of gas turbine blade shroud interlocks LIM-1, pp 213-218

2. Köhler H, Partes K, Seefeld T, Vollertsen F (2010) Laser reconditioning of crankshafts: from lab to application. Phys Procedia 5:387-397

3. Leyens C, Brückner F, Nowotny S (2012) Innovations in laser cladding and direct metal deposition. Laser and tera-Hertz Science and Technology (pp. MF2B-1). Opt Soc Am

4. Nowotny S, Scharek S, Beyer E, Richter KH (2007) Laser beam build-up welding: precision in repair, surface cladding, and direct 3D metal deposition. J Therm Spray Technol 16(3):344-348

5. Toyserkani E, Khaiepour A, Corbin S (2004) 3-D finite element modelling of laser cladding by powder injection: effects of laser pulse shaping on the process. Opt Lasers Eng 41:849-867

6. Volpp J, Hohenäcker V, Tyralla D, Freisse H, Brocke N, Silze F, Schnick M, Thomy C (2017) Observing melt pool temperature fields for process characterization. Proceeding of Lasers in Manufacturing Conference 2017, Munich, Germany

7. Han L, Phatak KM, Liou FW (2004) Modeling of laser cladding with powder injection. Metall Mater Trans B 35(6):1139-1150

8. Peyre P, Aubry P, Fabbro R, Neveu R, Longuet A (2008) Analytical and numerical modelling of the direct metal deposition laser process. J Phys D Appl Phys 41:025403 (10pp)

9. Pinkerton AJ (2007) An analytical model of beam attenuation and powder heating during coaxial laser direct metal deposition. J Phys D Appl Phys 40:7323-7334
10. Qi H, Mazumder J (2006) Numerical simulation of heat transfer and fluid flow in coaxial laser cladding process for direct metal deposition. J Appl Phys 100:024903

11. Partes K (2008) Hochgeschwindigkeitsbeschichten mit dem Laserstrahl. Strahltechnik Band 34, BIAS Verlag

12. Jouvard JM, Grevey DF, Lemoine F, Vannes AB (1997) Continuous wave Nd: YAG laser cladding modeling: a physical study of track creation during low power processing. J Laser Appl 9(1):43-50

13. Volpp J, Prasad, HS, Kaplan A (2018) Behavior of heated powder particles on solid surfaces. In: Proceeding of the $8^{\text {th }}$ Swedish Production Symposium, SPS 2018, 16.-18. May 2018, Stockholm, Sweden, Paper 9

14. Lin J (1999) A simple model of powder catchment in coaxial laser cladding. Opt Laser Technol 31(3):233-238

15. Volpp J, Prasad HS, Riede M, Brueckner F, Kaplan A (2018) Powder particle attachment mechanisms onto liquid material. In: Proceeding of the 10th Conference on Photonics Technologies LANE 2018 (accepted)

16. Keene BJ (1993) Review of data for the surface tension of pure metals. Int Mater Rev 38(4):157-192

17. Schönecker S, Li X, Johansson B, Kwon SK, Vitos L (2015) Thermal surface free energy and stress of iron. Sci Rep 5:14860

18. Gatzen M, Radel T, Thomy C, Vollertsen F (2014) Wetting behavior of eutectic Al-Si droplets on zinc coated steel substrates. J Mater Process Technol 214(1):123-131

19. Mizukami H, Hayashi K, Numata M, Yamanaka A (2012) Prediction of solid-liquid interfacial energy of steel during solidification and control of dendrite arm spacing. ISIJ Int 52(12):22352244

20. Pinkerton AJ, Li L (2004) An analytical model of energy distribution in laser direct metal deposition. Proc Inst Mech Eng B J Eng Manuf 218(4):363-374

21. Brands EA, Brook GB (1992) Smithells metals reference book. Butterworth-Heinemann Ltd., Oxford

22. Specht E (2008) Grundlagen der Wärme- und Stoffübertragung. Manuscript. Otto-von-Guericke University Magdeburg, Magdeburg

23. Weirauch DA, Krafick WJ, Ackart G, Ownby PD (2005) The wettability of titanium diboride by molten aluminum drops. J Mater Sci 40:2301-2306 